\title{
An 'ecospiritual' perspective: Finally, a place for Indigenous approaches
}

\author{
John Coates, Mel Gray and Tiani Hetherington
}

\begin{abstract}
John Coates, Professor of Social Work, St Thomas University, New Brunswick, Canada Mel Gray, Professor of Social Work, University of Newcastle, New South Wales, Australia Tiani Hetherington, PhD student, University of Newcastle, New South Wales, Australia
\end{abstract}

\begin{abstract}
Despite holding significant roles in providing social services to First Nations or Indigenous communities, social work has been reluctant to accept Indigenous perspectives and traditional forms of helping and healing. Most often, social workers have operated within the dominant paradigms that, despite efforts to the contrary, have primarily imposed western social work beliefs and practices which have been unable to effectively accommodate diversity. This paper argues that the recent attention to the importance of the environment and spirituality, and the paradigmatic shift that such issues require, has created a welcoming space for Indigenous voices. Such acceptance has opened the opportunity for the profession to benefit not only from a genuine exchange among cultures, but also from a re-thinking of the foundational beliefs of the social work profession.
\end{abstract}


Social work education and practice, in regards to Indigenous groups, has struggled to develop and deliver social work services in an effective, acceptable and culturally relevant manner (Gray, Coates and Hetherington, 2007). Most often such efforts have relied on dominant western paradigms and, as a result, have been unable to accommodate diversity. Professional social work literature that has reviewed such cross-cultural ventures with First Nations and Indigenous groups has revealed largely negative results (Hart, 2002; How Kee, 2003, 2004; Nagpaul, 1993; Nimmagadda and Cowger, 1999; Tsang and Yan, 2001; Yip, 2004). In the main, social work has acted as an agent of colonisation, especially in transferring inappropriate mainstream theory and practice models to work with Indigenous groups (see Haug, 2001, 2005). Perhaps nowhere else has this been so vividly demonstrated as in child welfare where mainstream criteria, values, standards, and interventions continued the process of colonisation.

Cross-cultural, anti-racist and anti-oppressive practice have made headway as these approaches have enabled social work to look carefully at its own practices and to develop more responsiveness to Indigenous ways of knowing, helping and healing. However, much of this work appeared as adaptation rather than exchange as modernist social work had great difficulty welcoming and accommodating diversity (see Coates 2003; Healy 2001; Haug, 2001, 2005). This lack of responsiveness occurred in dealings with Indigenous groups both within western countries where 'the human services have contributed to the practices of colonization and dispossession' (Healy, 2000, p. 61), as well as in countries where economic development efforts 'laid the foundation for intellectual colonization in which western modernist scientific knowledge systems 
displaced previously established local, popular and Indigenous knowledge systems' (Haug, 2001, p. 44).

This paper argues that the difficulty in adequately addressing diversity stems from social work's preference for modernist, ethnocentric (i.e. Euro-American) paradigms which define rules for acceptable knowledge and practice. This has contributed not only to intellectual colonisation, but also to the devaluing and marginalisation of Indigenous and local knowledge. Thus 'through professional imperialism, modern institutional models of social care replaced the tremendous diversity of traditional models of social care' (Haug, 2001, p. 44 italics in original). To explore why social work has struggled to accommodate diversity we turn to the cross-cultural social work literature and its attempts to respond to cultural diversity, not least through anti-oppressive practice.

\section{Social Work's Struggle with Diversity}

Social work's literature on cross-cultural practice is built on the assumption that ‘culturally appropriate interventions’ (Boyle and Springer, 2001, p. 56) depend upon the social worker's acquisition of a particular body of cultural knowledge, values and skills (see Clark, 2000; Devore and Schlesinger, 1995; Lum, 1999; Weaver, 1998, 1999). Weaver $(1998,1999)$ argues that 'cultural competence' develops from a social worker’s knowledge about the specific cultural group, self-reflection and sensitivity to one's own biases. Transactional learning (Miller, 1988) or ‘bicultural integration’ (Lum, 1999) reflect culturally-specific knowledge, values and skills that lead to an understanding of other perspectives and cultures. This knowledge is then used by the social worker to understand the client’s ‘cultural frame of reference’ (Clark, 2000, p. 1). The central task 
in cross-cultural practice has been to integrate this knowledge and reflective understanding with practice skills so as to lead to culturally sensitive or culturally competent social work practice. However, writers (see for example, Hart, 2002; Prasad and Vijayaslakshmi, 1997; Tsang and Yan, 2001) from diverse contexts (in this case Canada, India and China, respectively) argue that micro-based cross-cultural models which emphasise rationalism and individualistic approaches are inappropriate in the context of non-western cultures:

This emphasis on rationality can be detected in both orthodox and critical social work discourses. The claim is that in its blind faith in the truth claims of modernity, social work has played a critical role, alongside all other human services, such as medicine, law, nursing, education and the therapies, in the practices of surveillance and disciplining. ... Human service organizations ... are oriented toward the normalization of deviant populations (Healy, 2000, p. 59).

Healy (2000) goes on to argue that even critical social work has trouble taking seriously the importance of local contexts in shaping practice since it is 'premised on the idea that there is a unified and identifiable set of critical practices' (p. 125). Such firmly held modern presumptions interfere with the acceptance of alternative, locally based practices. Critiques such as these led Haug (2001) to conclude that 'through the process of professional imperialism, the Western model of social work was transferred to postcolonial nations around the world' (p. 59). This technology transfer occurred with the 
support of the UN and international humanitarian organisations despite the recognised 'need to promote indigenous methods, curricula and study material' (Nagpaul, 1993, p. 217). 'Thus, even among IFSW member countries, often a majority of social workers are excluded due to the lack of professional qualifications' (Haug, 2001, p. 69). When there is such an imbalance of power, exchange is almost impossible to achieve (Haug, 2001).

Zachariah (cited in Haug, 2001, p. 116) argues that intellectual and cultural colonisation in support of corporate capitalism and globalisation constitutes the third wave of imperialism. 'The development literature is replete with examples of the way in which the homogenizing effects of universal aid has dramatically altered the security and sustainability of local socio-economic and cultural practices’ (Gray et al, 2007). Recent efforts by the IASSW and IFSW to establish global education standards are consistent with globalisation and downplay the relevance of local contexts (Gray and Fook, 2004; Gray, 2005). The essential problem with globalising standards is that they assume that the western approach should be treated as a universal perspective. Within this context disagreements are generally couched in terms of cultural relativism versus universalism.

Professionalising trends define boundaries serving to keep out those who do not conform. For example, the emphasis on individualisation and individual work, internal causality, dualism, rational determinism, as well as social work's professional interest to increase its status in society, marginalise local and Indigenous knowledge. Research indicates that it is impossible for persons to be treated justly or fairly when universalistic criteria are applied within bureaucratic structures (Sjoberg and Vaughan, 1993). The needs of local communities and marginalised groups to whom we are expected to be responsive and accountable are not, in practice, priorities. Grassroots movements in 
support of Indigenous groups most often involve people collectively asserting their rights for self-determination and political control. Self-determination for Indigenous people

may best be seen as the empowerment of entire populations. Political, economic, educational, and health benefits and privileges cannot occur when an entire population group is disenfranchised. The potential of individuals cannot be advanced without consideration of historical, social, cultural, economic, and political realities.

\section{Cultural awareness, cross-cultural and anti-oppressive practice}

A brief historical overview of efforts to accommodate diversity within the social work literature is evident in trends from multiculturalism to cultural and ethnic sensitivity to cross-cultural to transcultural and anti-oppressive practice. However, all have reached a theoretical impasse since a paradox exists as the foundational, universalising beliefs of mainstream social work have not been successful in accommodating or integrating First Nations' or Indigenous perspectives and modes of helping and healing. Even when professional education programs profess an openness to Indigenous models, often only mainstream social work models are taught and, First Nations students are left to accommodate traditional methods as best they can.

Social work expounds values and beliefs, such as universalism, professionalism and individualism, to name a few, that run counter to many Indigenous beliefs and values (such as interdependence and inclusion). If foundational beliefs were challenged, 'mainstream' social work would be pushed to critically explore foundational assumptions such as these. Clearly, the wealth of publications on cultural sensitivity, and crosscultural, anti-oppressive and anti-racist practice, attest to this struggle with diversity. 
Social work interventions must adapt to the realities encountered by Indigenous groups realities that are frequently 'unstable, complex and disorderly’ (Healy, 2000, p. 137) and value their diverse contributions. While postmodernism has encouraged marginal voices, its tendency to cultural relativism prevents it from advocating forcefully for change in any particular direction. Postmodernists do not take sides nor do they specify what must be done. As a result, conservatism has re-emerged in social work at a time when the profession needs to be 'challenged to not only expand its scope of inclusion but to actively reverse the colonialist direction of knowledge transfer’ (Haug, 2001, p. 135). We contend that social work will never be able to incorporate diversity effectively until it moves beyond dualistic and deterministic beliefs that separate professional knowledge and lived experience, and that stand in the way of seeing Indigenous perspectives as legitimate and credible.

Mainstream practice models, such as cross-cultural and anti-oppressive practice, which are most often used in discourse relating to minority and Indigenous cultures, are constructed from the perspective of the dominant culture. As such they have noble intentions to create an understanding of the way in which dominant cultures marginalise, oppress and exclude minority cultures, but they do so in such a way that it is almost impossible for minority cultures to lose or shake-off their victim status. These approaches are informed by critical and structural theory which have as their primary focus changing unjust and oppressive structures and practices in society. Giddens (1994) criticises them for the lack of agency they accord so-called oppressed groups in society. He distinguished between life politics, which is about individual choice and self-actualisation and gives the individual 'agency', and the old left and right emancipatory politics 
characteristic of most radical or critical social work discourse. 'In emphasizing the negative impact ... of structurally limited life chances’ (Ferguson, 2001, p. 47) an antioppressive perspective overlooks people's ability to rise above their circumstances. Within the spirituality and Indigenous social work literature, there is a greater recognition of the centrality of community, of 'individual agency' and of 'enhancing the capacities of (vulnerable) clients to practise effective life-planning, find healing and gain mastery over their lives’ (Ferguson, 2001, p. 41). These strengths-based approaches, while not denying the importance of structural factors, reinforce notions of choice and responsibility, most notably self-determination, seeing individuals as self-governing agents rather than powerless victims of oppressive forces. These approaches somewhat narrow social work’s revolutionary mission to change the world, society, organisations, and policies although this might still be part of what social workers do - and bring it back down to individuals and families and the communities in which they live. It is at this local level where tension is generated by the inappropriateness of western, universalising and globalising approaches (Haug, 2001, 2005).

This is most starkly demonstrated within child welfare practice, both in Canada and Australia, where First Nations and Indigenous communities are resisting mainstream criteria, values, standards, and interventions which have, historically, been detrimental to Indigenous communities and family life. The starkest examples are the Stolen Generations in Australia, and residential schools in Canada (see Milloy, 1999), both borne of the government's attempt to integrate Aboriginal children into white society by removing them from their families and communities. In both contexts organisations 
within Indigenous child welfare have been involved in the development of Indigenous practice standards for Indigenous child welfare (Gray and Valentine, 2005).

How then must one regard the critical discourse on social work's internationalising quest? What must we think about the dominance of the English language; the focus on rationalism; the rigid expectation of formal academic training and its corollary, expertise based in white North Americans and Europeans; the economic privilege of western academics with access to travel and money leading to a dominance of western academics and western methods and concepts? For example, Haug (2001) is critical of the transfer of knowledge from the west through the spread of professional schools, established mainly by the British and North Americans. Nagpaul (1993) is critical of professional training with its tacit assumption that 'the US social work philosophy is somewhat superior, and that principles and methods of US social work provide the only model which has universal applicability’ (p. 217). Smith is critical of the 'globalization of knowledge and Western culture (which) constantly reaffirms the west's view of itself as the centre of legitimate knowledge, the arbiter of what counts as knowledge and the source of “civilized” knowledge' (cited in Hart, 2002, p. 29). How might an alternative 'ecospiritual' approach, more compatible with Indigenous perspectives, help social work deal effectively with diversity? To answer this we need to turn to a different body of literature pertaining to so-called less developed contexts where many of our Indigenous communities are to be found. 


\section{Globalisation, Modernisation and Development}

Critical perspectives on globalisation, modernisation and development see social work's participation in so-called less developed contexts in a negative light since they have largely accompanied efforts to transfer western technology and practices to the rest of the world, often with disastrous effects on the environment and local cultures. Thus while such efforts were frequently encouraged by the expressed purposes of improving standards of living, progress and promoting trade, they often brought about the disruption of traditional family and community structures. As 'development' proceeded in the 'less developed' regions of the world, phrased in terms of modernisation, it set up a tension between the favoured 'modern' versus a 'traditional Indigenous' way of life. The modern was often regarded as more civilised and progressive than traditional Indigenous ways of life which were embedded in local cultures and seen as backward in some way. Thus said Pearce (2001), modernisation theory (coined by western sociologists) assumed that 'traditional societies did not have an innate capacity to become modern and, therefore, required assistance through the massive infusion of western values, technology, institutions, and policy making' (p. 50). The juxtaposition of the traditional/modern and the western/non-western are premised on the view that European culture is the pinnacle, superior to traditional (primitive) cultures. As a consequence, development planning, with its focus on altering traditional beliefs and practices, took place under the guise of 'rational behavior and accountability' (Hoogvelt, in Pearce, 2001, p. 50).

While modernisation began with colonialisation and persists with globalisation, this need not be negatively construed. Clearly, calls for indigenisation in Africa are 'motivated by a genuine desire to preserve the indigenous culture of peoples whose 
confidence in themselves has been undermined by colonialism' (Wiredu, 1980, p. 40). In a sense, to decipher a post-colonial identity, some aspects of traditional culture need to be re-found and, in post-colonial situations, there is a need to break free of western conceptions so that people can recover their own cultural identity (Wiredu, 1980). Given the non-literate nature of the culture, where else can they find it than in the rediscovery of the 'old', indigenous ways of knowing grounded in the cultures of people in local contexts? Sifting through this and working out what fits the transition from traditional to modern is a process wherein a new culture will emerge which will be distinctly African. Thus, says Wiredu (1980), in these situations, 'uncritical exhortations to Africans to preserve their indigenous culture are not particularly useful - indeed, they can be counterproductive. There is an urgent need in Africa today for the kind of analysis that would identify and separate the backward aspects of our culture from those worth keeping' (p. 41). We need to guard against demonising western ways and romanticising indigenous ways. As Wiredu (1980) notes, there are advantages to modernisation just as there is a need to change outmoded traditional customs which do not conform to international human rights standards (Pearce, 2001). In this respect, social workers have a role to play in questioning unjust cultural practices. However, a sensitive way of doing this needs to be found for, as Gray and Allegritti $(2002,2003)$ note, resistance to new forms of colonialism in Africa arise when people think that ideas are being imposed on them without regard for their culture and they will resist and challenge such cultural imperialism. In post-colonial situations most indigenous people are engaged in a quest for their post-colonial identity, seeking to reclaim and preserve the best parts of their culture and traditional ways of life, hence the African Renaissance. In this sense, the shake-up 
which led to the cultural dislocation of indigenous life to which Pearce (2001) alludes still persists today but this need not be a bad thing. Culture is always changing in response to changes in broader society and, as Wiredu (1980) and Ramphele (2002) so eloquently point out in relation to Africa, there is a need to get rid of outmoded customs and anachronistic cultural practices.

More broadly, there are those who argue that modernisation and globalisation have contributed to development and reduced poverty in the Third World (Bhagwati, 2004; Melnik, 2004; Norberg, 2003; Patten, 1998; Sen, 2000; Wolf, 2004). Granted these writers are working on measures of extreme poverty in terms of which people are living on one US dollar a day, nevertheless, they claim that through the nineties the number of people living in abject poverty dropped from 1.29bn to 1.17bn with a World Bank (in Kane-Berman, 2005) projected drop to $809 \mathrm{~m}$ by 2015 . 'The last three decades have seen a reversal of roles between Africa and Asia: in the 1970s, 11\% of the world's poor were in Africa and 76\% in Asia. By 1998, Africa accounted for 66\% of the poor while Asia's share had declined to 15\%' (Kane-Berman, 2005, p. 2). This trend is seen as a direct result of economic growth and liberalisation in Asia where, from 1975-2002, the GDP doubled in India and quadrupled in China. Thus said UN Secretary General, Kofi Annan, at the UN Conference on Trade and Development in 2000: 'The main losers in today's very unequal world economy are not those who are too much exposed to globalisation. They are those who have been left out' (as cited by Kane-Berman, 2005, p. 3). Nevertheless, development is a pre-condition for growth. Kane-Berman (2005) cites Amartya Sen who identified national government responsibilities, such as the 
emancipation of women, and the provision of adequate education and health care as prerequisites for growth.

However, a one-sided analysis in terms of economic growth overlooks key quality of life issues. Eckersley (2005) defines 'quality of life' as 'the opportunity to experience the social, economic, cultural and environmental conditions that are conducive to total well-being - physical, mental, social, (and) spiritual' (p. 8). This broader perspective does not accord economic growth overriding priority neither is it concerned only with human development. Its concern is sustainable development, by which is meant a 'better balance and integration of social, environmental and economic goals and objectives to produce a high, equitable and enduring quality of life' (p. 8). And this cannot be achieved by people living on one US dollar a day.

This broader 'quality of life' perspective reflects a shift in values and ways of life away from gross materialism. It reflects a shift to post-materialist values which, while still valuing an adequate material standard of living, nevertheless give priority to environmental protection and cultural issues, even when these goals conflict with maximising economic growth. It also reflects moral concerns and the emergence of a more socially responsible and engaged individualism framed and shaped within a wider social context. Within this 'creative universe' (Giddens, 1991), individuals and social movements are taking responsibility for the design of their personal, social and planetary future. This post-materialist paradigm represents a shift away from a way of life framed by material progress based on self-interested competitive individualism, which has created a "shallow" democracy ... (and which) reduces social cohesion, weakens families and communities, and so diminishe(s) quality of life and wellbeing' (p. 8). The 
alternative 'quality of life' perspective is framed by sustainable development and based on altruistic, co-operative individualism, which will give rise to a "deep" democracy, greater social cohesion, strong families and communities, and so heightened quality of life and wellbeing' (p. 8). It is our contention that this 'alternative perspective' is beginning to permeate the social work literature enabling social work to be far more compatible with Indigenous perspectives which are finally being given a voice in the literature on spirituality and environmental or eco-social work. Within social work we call this the 'ecospiritual' perspective to distinguish it from the more narrowly conceptualised, anthropocentric ecological perspective. Healy (2000) describes three waves of systems theory in social work, namely, general systems theory, the ecosystems perspective and complex systems theory, the latter reflecting recognition of the creative, nonlinear and unpredictable nature of change and of intuitive knowledge. The eco-social and 'ecospiritual' perspective moves us beyond the individualistic focus of much of this theory in social work to a much broader holistic understanding of our world and one more akin to that of traditional and Indigenous societies and cultures. To this extent it might be viewed as an intuitive understanding on the part of these cultures as to the way the world works and our part in it.

\section{Spirituality and Ecology: A Welcoming to Alternative Perspectives}

The recent emergence of literature on spirituality and environmental or eco-social work has provided not only a refreshing break from the afore-mentioned 'inferiorisation' processes, but also, and more importantly, it is creating a space where Indigenous voices are being heard. The resurgence of interest in the areas of spirituality and the 
environment has taken place in many professions and, to some degree, in general society as already outlined. It has been fueled by many factors, most notably, concerns about security in light of terrorism, the search for meaning in response to postmodernism's critique of grand schemes and solutions, and warnings of environmental degradation. In recent years, conferences on spirituality have been hosted by a wide array of professions, such as counseling, medicine, business, and social work. Environmental issues have achieved widespread public attention, most recently due to the Kyoto Protocol coming into effect in 2005.

Spirituality and ecology emphasise, respectively, a search for meaning and sustainability, and acknowledge the need to accept and value alternative perspectives. The acceptance of these alternative knowledge systems has created a 'welcoming and inclusive context enabling the celebration of diversity, and the sharing of knowledge' (Gray et al, 2007). Person-in-environment expands to assume an interdependence and relatedness of all life, connectedness with nature, and the importance of place. These values are not only consistent with more traditional Indigenous knowledge systems (see for example, Four Worlds Development Project 1982; Graveline, 1998; Hart, 2002), but also provide an accepting environment for Indigenous forms of healing and helping.

While social work, in recent years, has been attentive to issues of spirituality, due in particular to the contributions from Ed Canda and others (Canda, Nakashima, Burgess and Russel, 1999; Canda and Furman, 1999), the profession has been slow to become engaged in the environmental movement. This is possibly due to its narrow interpretation of the environment in the 'person in environment' to be almost exclusively social (see Besthorn, 1997; Coates, 2003). This restricted vision, along with the primary emphasis in 
practice on individualism and urban social realities, has contributed to the profession perceiving environmental issues as lying beyond its jurisdiction and being reluctant to recognise the severe impacts of ecological devastation on such things as quality of life, personal and community relationships, and social policy. However, as the profession's scholarship looks more seriously and substantially at environmental issues (see Besthorn, 2003, Coates, 2004; Hoff and McNutt, 1994; Rogge, 2000) and social work’s reluctance to be involved (Besthorn, 1997; Coates, 2003), it becomes clear that many social workers are challenging the modernist boundaries of the profession, and seek a more inclusive framework within which social work can more effectively be involved in issues of ecological decline and sustainability.

Several scholars have critiqued the foundational assumptions of modernity (Adams, 1993; Berry, 1999; Spretnak, 1997). Some schools of thought, such as ecofeminism (Plant, 1989), philosophy (Naess, 1989), social work (Coates, 2003) and deep ecology (Devall and Sessions, 1985), have advocated the need for a new foundation of beliefs and values, a new paradigm to guide human activity and bring it into harmony with the life-processes of Earth. Several of these scholars recognise the important contribution made by traditional Indigenous beliefs and values. 'As a result, indigenous beliefs and values have gained recognition and credibility among the world views which provide a reconceptualisation of the universe and humanity's relationship to it. In social work this has opened avenues of acceptance toward indigenous approaches to helping' (Gray et al, 2007).

Evidence of the growing attention and recognition of Indigenous knowledge systems, practices, and scholarship can be found in the frequent and constructive 
references to Indigenous knowledge in social work scholarship in these areas (Besthorn, 2004; Coates, 2003; Zapf, 2005), articles in professional journals (for example, Currents: New Scholarship in the Human Services, 2003, 2004; Critical Social Work, 2003, 2005) and the number of presentations at conferences dealing with spirituality and ecology in Canada, the United States and internationally.

\section{Opening up Mainstream Social Work to an Alternative Perspective}

While an alternative perspective may be unacceptable to many social workers, there is, nevertheless, much to be gained from the tensions which arise from exploring diverse perspectives and approaches. Given social work's diversity, these tensions are inevitable and have a balancing or evening out effect, preventing us from sinking into a regressive bipolar dis-order. We have not done ourselves any good by polarising debates and casting ourselves as reactionaries or progressives, rationalists or Marxists, community or clinical practitioners, and so on. Rather we have much to learn from the diverse experiences and contexts in which we practice, whether we are working in mainstream western or local Indigenous practice contexts (Gray et al, 2007). Western social workers need to become aware of the impact of globalisation and international 'development' efforts that fail to embrace or recognise local knowledge and methods. Those working in Indigenous contexts need to reflect on the universals in social work that apply regardless of the contingencies of local culture. There is room for shared understanding and agreement on values relating to human rights and social justice. The recognition and acceptance of diversity within the social work discourse can then be translated into practice approaches which enable the profession to move forward to take a more significant place in the many 
cultures around the world. United in this way, social work is better situated to move beyond the constraints of individualism, dualism and determinism to a more effective position where, with a single voice, we might propose policies that lead toward effective and beneficial social change.

\section{Alternative foundational beliefs}

Social work can enhance its potential for change by not only reflecting critically on its unexamined support of modernism, but also by re-defining its foundational beliefs and values. Such an alternative foundation has been presented by Berry $(1988 ; 1999)$ and has been reflected in the work of others, including Besthorn (2002), Clarke (1989, 2002), Coates (2003), Devall and Sessions (1985), Hubbard (1998), Plumwood (1993), Rozak (1992), and Suzuki and Knudtson (1992). While arising among writers concerned about environmental and social injustice, this perspective is based on the understanding that Earth, like the Universe itself, is emerging or unfolding. It arises from a belief that humans are part of the web of life and share a common destiny with the Earth, and in this context seeks a new understanding of what it means to be human. The core assumptions of this alternative include interdependence, emergence, diversity, and the feminist ethics of care with its relational concerns about the maintenance of interpersonal connections as well as the protection of human rights (Warnke, in Meehan, 1995).

In terms of this relational view, everything is interdependent and connected and, within an overarching and integrated whole, there are many overlapping and interlocking subsystems, for example, families, villages, cultures, economies, and ecologies. While all living beings may be conceived as independent in particular contexts, they are also tied 
into many systems. This innate relational tendency leads all organisms to co-exist in a state of belonging; organisms thrive in the midst of mutually beneficial and supportive relationships. Belonging is essential for the growth and development of all life forms and each organism achieves its unique identity in relationship (Clarke, 2002; O’Murchu, 1997). To understand one part you must understand how that part is connected to other parts (Hart, 2002). The larger environment is seen to support the unfolding of each member's full potential, and as each subsystem (both individual and community) achieves his/her/its unique potential (or individuality) they contribute to and help shape the larger environment.

When environments are well-functioning, interdependence supports and is reinforced by individuality, and both contribute to ongoing emergence through the increase of diversity and complexity (see Berry, 1988; Coates, 2003). Through these interactions every being plays a role in their own emergence and that of the whole. The challenge for social work is to nurture the creation of social 'structures which enable the self-unfolding of all its members in the context of a healthy Earth' (Coates, 2003, p. 73). Such emergence requires only that attention to one part does not work to the detriment of other parts.

The principles of Indigenous cultures (Four Worlds Development Project, 1982; Hart, 2002) such as wholeness, harmony, balance, and a close relationship of the physical and spiritual are consistent with the foundational beliefs of interdependence and emergence. The diversity of cultures throughout the planet 'demonstrates the great value of different life-styles and traditions and how these are so often well-adapted to the demands and limitations of particular habitats' (Coates, 2003, p. 81). 
The value of diversity leads to the feminist notion of ethics of care both out of enlightened self-interest and the innate rights of other species. In the globalised world it becomes easier to recognise that the well-being of people in all parts of the planet is dependent upon humans expanding our capacities to care for, and feel empathy for, other people (and other living beings). A concern for the well-being of all in the context of interdependence leads to an understanding that individual well-being can only be maximised in the context of, and accompanied by, community well-being. Personal fulfillment is not an isolated event. Concern for other people and other beings can be a great source of pleasure and fulfillment, and help us to transcend the exclusivity and selfinterested individualism of modernity. Interdependence, emergence, and the feminist ethics of care manifest an inclusive spirituality that is based on the intimate connection among the human, the Earth and spirit (see Besthorn, 2002).

These assumptions demand a whole system consciousness, what Earley (1997) refers to as global consciousness, which involves the recognition of the importance of other people and of other species to the global community. The challenge for us, personally and professionally, is to participate in the individual and communal struggle to live in the knowledge of our essential connectedness to the Earth; this includes a moral responsibility to live harmoniously within the biosphere (Berger and Kelly, 1993). At a personal level, it requires that we have a sense of our deep connection to all beings; a compassionate awareness that our individual and collective actions are intimately linked, and can be constructively linked to the well-being of others. A basic expression of this 
connection to other beings can be found in actions that recognise that other people and other species not only have a right to live, but also the right to a reasonable quality of life.

This alternative perspective represents a significant shift in consciousness, and is a refreshing counter to modernity's human-centred exploitation. Such a communal perspective sees individuality in the context of the whole, and can serve as motivation to bring about a shift in personal lifestyle and social organisation that is both sustainable and socially just. However, while such a perspective may provide motivation, it is also essential to work toward the establishment of socio-political structures through which alternative values and beliefs can be put into practice.

\section{Learning from non-western cultures}

Given our claim that the alternative perspective we are expounding is more consistent with Indigenous ways than modernist or postmodern paradigms, this concluding section examines how social work might counter its ethnocentric tendencies and learn from those working outside the mainstream. To this end, examples are provided from non-western, Indigenous cultures. They include the Hawaiian Ho'oponopono family conflict resolution (Hurdle, 2002) as well as two examples of a relational perspective wherein there is a spiritual sense of interconnectedness, and an integration of ecological harmony and social responsibility (Crofoot, 2002; Sinclair, 2004).

\section{Ho'oponopono: A Family Conflict Resolution Process}

Hurdle (2002) provides a Hawaiian example of a culturally relevant family conflict resolution intervention called Ho'oponopono which provides an excellent illustration of 
the compatibility between western and Indigenous models. While it has similarities to the problem-solving process in social work, it is different in that it is based on a shared cultural tradition with understood roles for participants, a spiritual focus, and an impetus for resolution to restore harmony. The formal nature of the ritual lends an aura of solemnity and importance which is crucial to many forms of traditional healing and is reflective of the integration of spirituality with healing in many Indigenous cultures. Briefly, Ho'oponopono means setting to rights. It was originally performed in ancient Hawaii by kahuna (traditional healers) to maintain harmony in the community. The goal of the ho'oponopono is the restoration of harmony within the family and the development of a solution to the problem embedded in the traditional Hawaiian values of extended family, need for harmonious relationships and restoration of good will, or aloha.

The ho'oponopono is opened with a prayer, which is followed by the identification of the problem, both in a general and a specific manner. This includes a description of the hala, or transgression, and the negative entanglement, or hihia, thus created. Each participant who has been affected by the problem, either directly or indirectly is asked to share his or her feelings (mana'o). An emphasis is placed on selfscrutiny, honest and open communication, and avoidance of blame. The resolution phase begins with the mihi; this is a confession of wrongdoing and the seeking of forgiveness, which is expected. To establish mutuality, the wronged party also asks forgiveness for his or her reactions to the offense. This is a unique part of the process because all parties to the conflict ask forgiveness of one another, which establishes equal status among them. Restitution for the offense may be appropriate, and if so, a plan may be determined. The closing stage, pani, includes a summary of the process, a reaffirmation of the family's 
strengths and enduring bonds, and a final prayer. The problem that has been worked out is then declared closed and should not be brought up again. If subsequent sessions are needed to work out other layers of the problem, the final pani is delayed until that time.

\section{A relational perspective: Healing for First Nations Indigenous peoples}

Traditional Indigenous healing practices are embedded in a spiritual sense of interconnectedness which is fundamentally different from the dominant western paradigm in that 'Western models of healing separate and detach individuals from their social, physical and spiritual environments, isolating "patients" for treatment purposes and then re-introducing them into the world. Traditional healers are concerned with balancing emotional, physical, mental, spiritual, aspects of people, the environment, and the spirit world' (Hart, 1996, p. 63). To develop healing strategies that are culturally appropriate, Crofoot (2002) argues that social work practitioners need to be able to connect their knowledge and skills with the Indigenous 'relational perspective' in terms of which health and wellness constitute a balance of four major factors: the spirit, the context, the mind, and the body. Poonwassie and Charter (2001) describe several healing practices symbolic of cyclical interpretations of life and universal connectedness including The Medicine Wheel, The Wheel of Life, The Circle of Life, and The Pimatisiwin Circle. Among the four parts of these circles are physical, mental, emotional, and spiritual elements, four directions North, East, South, and West, and other aspects of interdependence and harmony. In the relational perspective, Spirit includes spiritual practices and teachings, dreams, symbols, stories, gifts, intuition, grace, protecting forces, and negative forces (Cross, 1998). Context includes family, culture, work, community 
history, and environmental factors, including climate and weather. Mind includes intellect, emotion, memory, judgment, and experience. Body includes chemistry, genetics, nutrition, substance use and abuse, sleep and rest, age and condition (Cross, 1998). Indigenous cultural identity and spirituality are deeply connected with land and place. The spiritual presence at each of these directions gives a specific type of wisdom, teaching and relationship to the world. These few examples do not represent the whole relational perspective; they offer only a glimpse of the types of forces that need to be in balance for an Indigenous person to experience a sense of well-being.

First Nations' integration of ecological harmony and social responsibility: A Canadian example

A traditional First Nations perspective is one where spirituality is intrinsically linked to philosophy, ideology and daily living. Two key concepts that underpin this First Nations' perspective are all my relations and the sacredness of life (Sinclair, 2004). All my relations is a foundational belief in this Indigenous cosmology which acts as a reminder of those to whom individuals are related in their immediate and extended family and community. This web of kinship extends to all animals and plants, the animate and inanimate. Moreover, this relational perspective is an encouragement to accept the social responsibility for living a harmonious and moral life in the present which comes with being part of a universal family (King, 1990) and in caring for and honoring the past - the suffering, memory and spiritual well-being of the dead - as well as taking care of the Earth for seven generations to come. Thus there is recognition of the interrelatedness and interconnectedness of all life forms since each has equal status and is subject to the same 
universal power. The second central notion is expressed through the belief that the sacredness of life is manifested in an array of behaviours integrated into daily life. In practice, this includes: sunrise ceremonies honoring the new day and simple prayers uttered during the day, to reverent ceremonies, such as the sundance and the sweatlodge (Sinclair, 1999). The sacred permeates all aspects of this Indigenous perspective which promotes the idea of a harmonious and balanced universe.

\section{Conclusion}

In this paper we have argued that the dominant western paradigms of the social work profession have failed consistently to be inclusive of local contexts, Indigenous knowledge, and traditional helping and healing practices. An 'ecospiritual' worldview is one that encompasses care and consideration for the well-being of all in the universe, and for the universe as a whole. Indigenous ecospiritual approaches, through an increased emphasis on spirituality and ecology, have been shown to provide innovations and meaningful insights as to ways in which to respond to the challenges facing the world, including the current ecological crisis. Resolving tensions in social work practice are important in the continuing search to find a stance that honors both commonality and diversity. It is through this process of interchange and rethinking the foundational beliefs that social work discourse may come to resemble a puzzle. The frame of the puzzle encompasses all views. However, each piece of the puzzle can be joined in a variety of ways to provide a different framework from which to view and accommodate diversity. We advocate for a culturally relevant, holistic approach that honours the diversity of local Indigenous knowledges but also allows for some universals. The emphasis here is on 
relationships, communities, spirituality, nature, and the environment, and real ecological sustainability. At the intersection of each connecting piece there is tension and creative synergy. This represents the need to understand our environment in spiritual terms, and to respect, express and celebrate our connectedness.

Figure 1: Theoretical framework for the eco-spiritual perspective

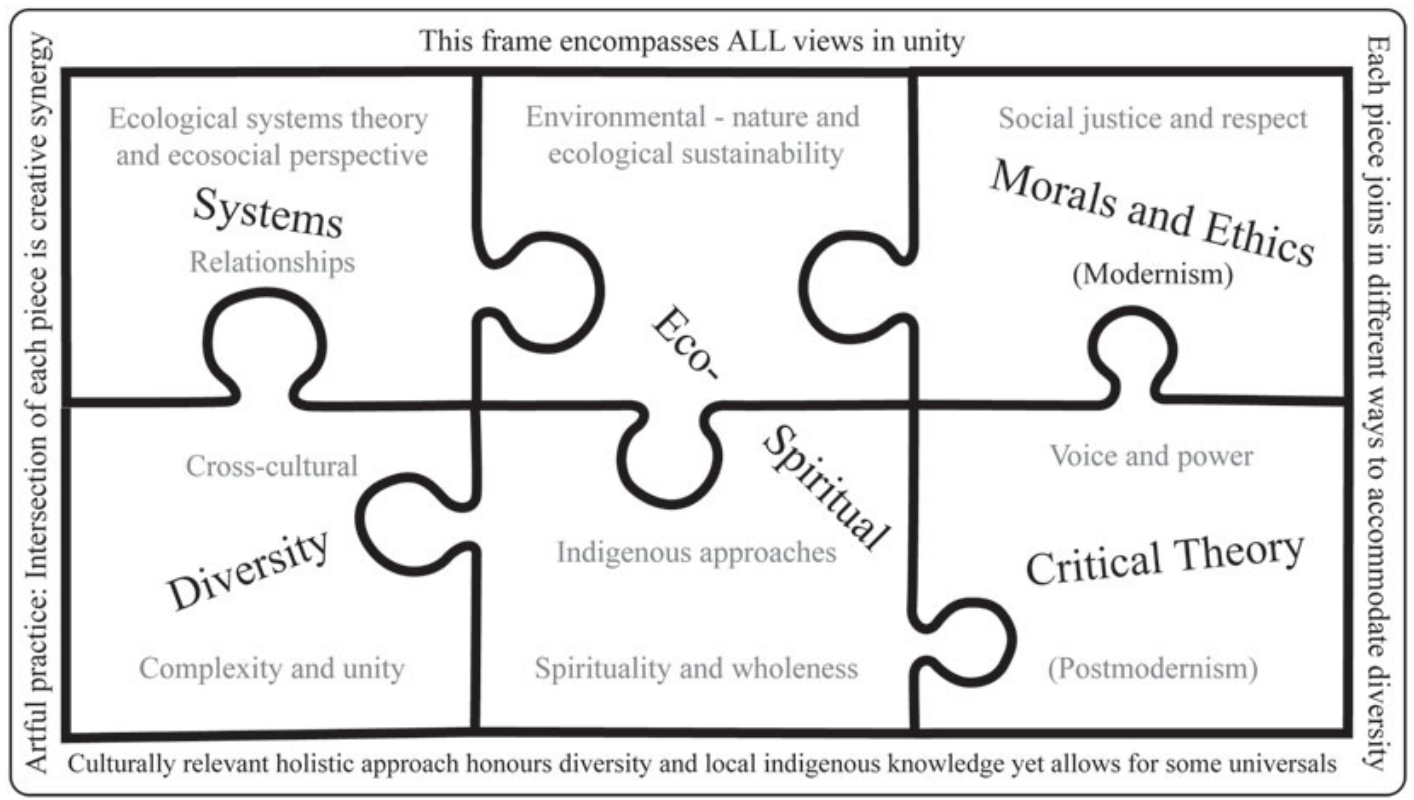

\section{References}

Adams, C. (1993) Ecofeminism and the sacred, New York, Continuum Publishing.

Berger, R. and Kelly, J. (1993) 'Social work in the ecological crisis’, Social Work, 38(5), pp. 521-526.

Berry, T. (1988) The dream of the earth, San Francisco, Sierra Club Books.

Berry, T. (1999) The great work: Our way into the future, New York, Bell Tower. 
Besthorn, F. (1997) Reconceptualizing social work's person-in-environment perspective: Explorations in radical environmental thought, $\mathrm{PhD}$ Dissertation, University of Kansas, Ann Arbor, UMI Microform 981157.

Besthorn, F. (2002) 'Expanding spiritual diversity in social work: Perspectives on the greening of spirituality', Currents: New Scholarship in the Human Services, 1(1), Retrieved April 15, 2005 from http://fsw.ucalgary.ca/currents/fred_besthorn/besthorn.htm

Besthorn, F. (2003) 'Radical ecologisms: Insights for educating social workers in ecological activism and social justice', Critical Social Work: An Interdisciplinary Journal Dedicated to Social Justice, 3(1), 66-106, Retrieved April 1, 2005 from http://www.criticalsocialwork.com/CSW20031.html

Besthorn, F. (2004) 'The parable of the tribes: On anarchy, peace and spiritual transformation', Spirituality and Social Work Forum, 10(2), pp. 1-6.

Bhagwati, J. (2004) In defense of globalisation, New York, Oxford University Press.

Boyle, D. and Springer, A. (2001) 'Towards a cultural competence measure for social work with specific population', Journal of Ethnic and Cultural Diversity in Social Work, 9(3/4), pp. 53-71.

Canda, E. R. and L. D. Furman (eds). (1999) Spiritual diversity in social work practice: the heart of helping, New York, The Free Press.

Canda, E. R., Nakashima, M., Burgess, V. and Russel, R. (1999) Spiritual diversity and social work: A comprehensive bibliography with annotations, Virginia, USA, Council on Social Work Education. 
Clark, J. (2000) Beyond empathy: An ethnographic approach to cross-cultural social work practice, Toronto, Faculty of Social Work, University of Toronto.

Clarke, M. (1989) Ariadne's thread: The search for new modes of thinking, New York, St. Martin’s Press.

Clarke, M. (2002) In search of human nature, New York, Routledge.

Coates, J. (2003) Ecology and social work: Toward a new paradigm, Halifax, Canada, Fernwood Press.

Coates, J. (2004) 'From ecology to spirituality and social justice', Currents: New Scholarship in the Human Services, 3(1), Retrieved April 15, 2005 from http://fsw.ucalgary.ca/currents/articles/articles/coates/index.htm

Crofoot, T. (2002) 'Using reasons for living to connect to American Indian healing traditions', Journal of Sociology and Social Welfare, 29(1), pp. 55-75.

Cross, T. (1998) 'Understanding family resilience from a relational worldview', in H. McCubbin, Thompson, E. Thompson, A. \& Fromer, J. (Eds), Resiliency in Native American and immigrant families, Thousand Oaks, CA, Sage Publications.

Devall, B. and Sessions, G. (1985) Deep ecology, Salt Lake City. Peregrine Smith Books.

Devore, W. and Schlesinger, E.G. (1995) Ethnic-sensitive social work practice, United States, Allyn \& Bacon.

Earley, J. (1997) Transforming human culture, Albany, New York, SUNY Press.

Eckersley, R. (2005) 'The challenge of post-materialism', The Weekend Australian Financial Review, March 24-28, 2005, pp. 5 and 10.

Ferguson, H. (2001) 'Social work, individualization and life politics', British Journal of Social Work, 31(1), pp. 41-55. 
Four Worlds Development Project (1982) Twelve principles of Indian philosophy, Lethbridge, Alberta, University of Lethbridge.

Giddens, A. (1991) Modernity and self-identity, Stanford, Stanford University Press.

Giddens, A. (1994) Beyond left and right,. Cambridge, Polity Press.

Graveline, F. (1998) Circle works: Transforming Eurocentric consciousness, Halifax, Fernwood Publishing.

Gray, M., Coates, J. \& Hetherington, T. (2007) 'Hearing Indigenous voices in mainstream social work’, Families in Society, 88(1), 53-64.

Gray, M. and Allegritti, I. (2002) 'Cross-cultural practice and the indigenisation of African social work', Social Work/Maatskaplike Werk, 38(4), pp. 324-336.

Gray, M. and Allegritti, I. (2003) 'Towards culturally sensitive social work practice: Reexamining cross-cultural social work', Social Work/Maatskaplike Werk, 39(4), pp. 312-325.

Gray, M. and Fook, J. (2004) 'The quest for universal social work: some issues and implications', Social Work Education, 23(5), pp. 625-644.

Gray, M. and Valentine, B. (2005) ‘Devising practice standards for Aboriginal out-ofhome care', Illinois Child Welfare, 2(1-2), 116-123.

Gray, M. (2005) 'Dilemmas of international social work: Paradoxical processes in indigenisation, imperialism and universalism', International Journal of Social Welfare, 14(2), pp. 230-237.

Hart, M. (1996) 'Sharing circles: Utilising traditional practise methods for teaching, helping and supporting', in S. O’Meara \& West, D. (Eds). From our eyes: Learning from Indigenous peoples, Toronto, Garamond Press. 
Hart, M. (2002) Seeking mino-pimatisiwin: An aboriginal approach to helping. Halifax, Canada, Fernwood Press.

Haug, E. (2001) Writing in the margins: Critical reflection on the emerging discourse of international social work, unpublished MSW Thesis, Faculty of Social Work, University of Calgary, Calgary, Canada.

Haug, E. (2005) 'Critical reflections on the emerging discourse of international social work’, International Social Work, 48(2), pp. 126-135.

Healy, K. (2000) Social work practices: Contemporary perspectives on change. Thousand Oaks, Sage.

Healy, L. (2001) International social work: Professional action in an interdependent world, New York, Oxford University Press.

Hoff, M. and McNutt, J. (1994) The Global environmental crisis: Implications for social welfare and social work, Brookefield, VT, Avebury.

How Kee, L. (2003) 'Drawing lessons from locally designated helpers to develop culturally appropriate social work practice’, Asia Pacific Journal of Social Work, 13(2), pp. 26-44.

How Kee, L. (2004) 'The search from within: Research issues in developing culturally appropriate social work practice’, International Social Work, 47(3), pp. 336-345.

Hubbard, B. (1998) Conscious evolution: Awakening our social potential, Novato, CA, New World Library.

Hurdle, D. (2002) 'Native Hawaiian traditional healing: Culturally based interventions for social work practice', Social Work, 47(2), pp. 183-192. 
Kane-Berman, J. (2005) 'Globalisation, sovereignty, and the role of the state’, Fast Facts April 2005, 2-6, Johannesburg, South African Institute of Race Relations.

King, T. (1990) All my relations: An anthology of contemporary Canadian Native fiction, Toronto, McClelland \& Stewart.

Lum, D. (1999) Culturally competent practice: A framework for growth and action. Pacific Grove, CA, Brooks/Cole.

Melnik, S. (2004) Freedom, prosperity and the struggle for democracy, Berlin, Liberal Institute.

Miller, J. (1988) The holistic curriculum, Toronto, Ontario Institute for Studies in Education.

Milloy, J. (1999) A National Crime: The Canadian Government and the residential school system, 1879-1986, Winnipeg, The University of Manitoba Press.

Naess, A. (1989) Ecology, community and lifestyle (D. Rothenberg, Trans. \& ed), Cambridge, Cambridge University Press.

Nagpaul, H. (1993) 'Analysis of social work teaching material in India: the need for indigenous foundations’, International Social Work, 36, pp. 207-220.

Nimmagadda, J. and Cowger, C. (1999) ‘Cross-cultural practice: Social worker ingenuity in the indigenization of practice knowledge', International Social Work, 42(3), pp. 261-276.

Norberg, J. (2003) In defense of global capitalism, Washington, DC, Cato Institute.

O’Murchu, D. (1997) Quantum theology, New York, Crossroads Publishing Company.

Patten, C. (1998) East and West, London, MacMillan. 
Pearce, T.O. (2001) 'Human rights and sociology: Some observations from Africa', Social Problems, 48(1), pp. 48-56.

Plant, J. (1989) Healing the wounds: The promise of ecofeminism, Philadelphia, New Society.

Plumwood, V. (1993) Feminism and the mastery of nature, London, Routledge.

Poonwassie, A. and Charter, A. (2001) 'An Aboriginal worldview of helping empowering approaches’, Canadian Journal of Counselling, 35(1), pp. 63-73.

Prasad, B. and Vijayaslakshmi, B. (1997) 'Field instruction for social work education in India: Some issues’, Indian Journal of Social Work, 58, pp. 72.

Ramphele, M. (2002) Steering by the stars: Being young in South Africa, Cape Town, Tafelberg Publishers.

Rogge, M. (2000) 'Children, poverty and environmental degradation: Protecting current and future generations', Social Development Issues, 22(2/3), pp. 46-53.

Rozak, T. (1992) The voice of the earth: An exploration of ecopsychology, New York, Touchstone.

Sen, A. (2000) Development as freedom, New York, Anchor Books.

Sinclair, R. (1999) Gender diversity in the 'Americas': Reconstructing a way of life, unpublished paper.

Sinclair, R. (2004) ‘Aboriginal social work education in Canada: Decolonising pedagogy for the $7^{\text {th }}$ Generation', First Peoples Child and Family Review, 1(1), pp. 49-61.

Sjoberg, G. and Vaughan, T. (1993) 'The ethical foundations of sociology and the necessity for a human rights alternative', in T. Vaughan, Sjoberg, G. \& Reynolds, 
L. (eds), A critique of contemporary American sociology, New York, General Hall, Inc.

Spretnak, C. (1997) The resurgence of the dead, Don Mills, Ontario, Addison-Wesley.

Suzuki, D. and Knudtson, P. (1992) Wisdom of the elders: Sacred native stories of nature, New York, Bantam Books.

Tsang, A.K.T. and Yan, M-C. (2001) 'Chinese corpus, western application: The Chinese strategy of engagement with western social work discourse', International Social Work, 44(4), pp. 433-454.

Warnke, G. (1995) 'Discourse ethics and feminist dilemmas of difference’, in J. Meehan (Ed), Feminists read Habermas: Gendering the subject of discourse, London, Routledge.

Weaver, H.N. (1998) 'Indigenous people in a multicultural society: Unique issues for human services’, Social Work, 43(3), pp. 203-212.

Weaver, H.N. (1999) 'Indigenous people and the social work profession: Defining culturally competent services’, Social Work, 44(3), pp. 217-227.

Wiredu, K. (1980) Philosophy and an African culture, Cambridge, Cambridge University Press.

Wolf, M. (2004) Why globalisation works, Hew Haven, Yale University Press.

Yip, K. (2004) 'A Chinese cultural critique of the global qualifying standards for social work education', Social Work Education, 23(5), pp. 597-612.

Zapf, M. (in press) 'Profound connections between person and place: Exploring location, spirituality, and social work’, Critical Social Work, 6(2). 
John Coates, PhD, is Professor of Social Work at St Thomas University in New Brunswick, Canada.

Mel Gray, PhD, is Professor of Social Work at the University of Newcastle in New South Wales, Australia.

Tiani Hetherington is a PhD student in social work at the University of Newcastle New South Wales, Australia.

Correspondence to:

John Coates, Department of Social Work, St Thomas University, Fredericton, New

Brunswick, Canada, E3B 5G3. Email: Jcoates@stu.ca

Mel Gray, School of Humanities and Social Science, University of Newcastle,

University Drive, Callaghan, 2308, NSW, Australia. Email: Mel.Gray@newcastle.edu.au

Tiani Hetherington, School of Humanities and Social Science, University of Newcastle, University Drive, Callaghan, 2308, NSW, Australia. Email:

Tiani.Hetherington@newcastle.edu.au 